Journal of the

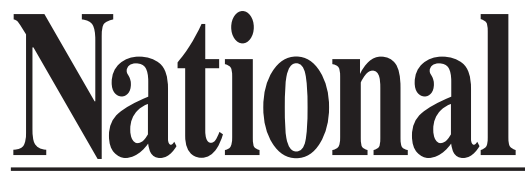

Academy or

Forensic
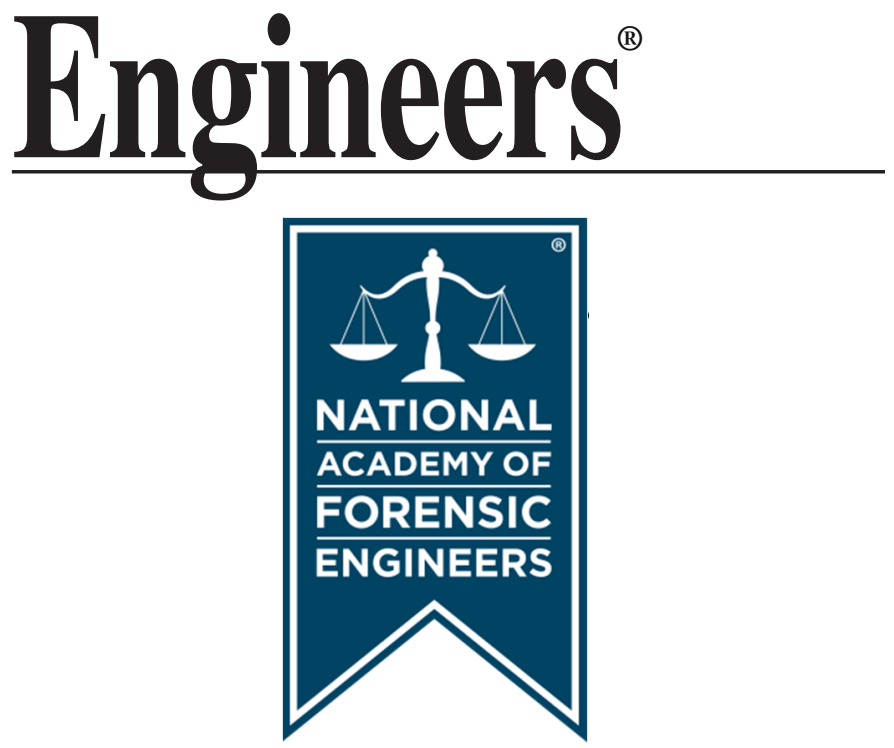

http://www.nafe.org ISSN: 2379-3252 


\title{
Construction for Hurricane Conditions
}

\author{
by W. T. 'Dusty' Yaxley, C.S.P., P.E. (NAFE 270F)
}

\section{Introduction}

Hurricanes have ravaged the Southeastern United States for hundreds of years. Large powerful hurricanes have seemingly blown apart even the best structures. In recent decades named storms like Donna, Camille, Hugo and Andrew have left vibrant memories with persons that have lived through them, as well as those that have only heard and seen images on the news coverage. Construction codes and restrictions have tried to keep pace with the damage generated by even a moderate hurricane's fury. Why has so much more damage been caused in recent years by these storm forces? Are the hurricanes getting more powerful, or has the construction became substandard? What should be done to avoid the widespread destruction experienced during Andrew? The answer is not simple because the problems are intertwined with many competing entities. We will explore those basic questions.'

After each natural disaster many questions are posed, often with competing studies, trying to answer how and what to do about reducing the damage and injuries caused by these awesome forces of nature. Invariability, well meaning groups advocate various ideas for solving these problems. The first and most usual solution has been to restrict development even further in areas where these high wind forces can be expected. Restricting development where hurricanes are likely to cause the most damage would require not building within a hundred miles or more from the ocean. This is an impossible goal to accomplish. Landowners want to develop that land and sell it to the people desiring to live in the susceptible areas. Removing all the development within a hundred miles of the coast in Florida would mean about 90 percent of the population would have to leave the state. While that may be desirable solution for some of the old timers, it is of course a practical impossibility. We will look at the questions of "can buildings be built to survive", and if so, "why don't we build them to survive such awesome fits of nature?"

\section{Code And Compliance Problems}

Code compliance has long been required for construction in most areas. The applicable code dictates what wind loads the designer is required to meet. The designer must designate the proper building materials and connections that would prevent failure of those buildings during a hurricane event. Engineers are 
well trained to design structures to withstand those prescribed wind loads. Manufacturers of building products and connections have done a remarkable job and provide many varied special products needed to comply with the code and engineers requirements. Building contractors can build structures to meet the engineer's plans and specifications, and thereby provide a safe building for the owners to live and work. Building departments require building permits and inspections to verify the buildings meet the plans and code requirements. Why then, do we have so much destruction when a hurricane passes through a populated area? Certain groups always state, "nothing can stand up to that kind of wind". Andrew, the most costly hurricane in Florida's history caused over 15 billion dollars of destruction, but high winds over $140 \mathrm{MPH}$ were confined to a small area. Many of the destroyed buildings were in the area of 90 to $110 \mathrm{MPH}$ winds. Many homes and businesses survived or had little damage due to Andrew's terrific winds. Why did some buildings sustain little damage and others were destroyed in the same area? The Miami Herald ${ }^{2}$ performed an intense comprehensive study after Andrew and uncovered some very solid, but unsettling evidence of why, in some areas the buildings fared better than others in adjacent areas. The most startling finding was that neighborhoods, even next to each other, varied widely in the damage suffered depending on how and when the buildings were built. Significantly less damage was suffered in buildings built before 1980 . Neighborhoods suffered distinctly different damage depending on the contractor or developer responsible. Winds, while very strong, were not strong enough to have caused so much devastation if the structures were built to meet the existing code. What happened after 1980 to cause this wide disparity in the building damage?

The South Florida political climate started to change in the late 1950's and continued changing through the 1980's. The developers had a much more sympathetic board of county commissioners that were very pro development. After all, Miami (Dade County, Florida) had the most stringent building code in the Southeastern United States hurricane zone. But no significant hurricanes had been felt in Dade County for decades. Some of the more significant changes included the following:

1. 1961, roof sheathing was no longer required to be nailed, but staples were approved.

2. 1970, wall board was no longer required to be plywood, but Masonite was approved.

3. 1980 , No. 30 felt was no longer required, but 2 layers of No. 15 felt was approved.

4. 1984, plywood sheathing was no longer required, but pressed board decking was approved. 
5. EIFS, (External Insulation and Finish Systems) became prevalent and acceptable.

6. New sealants were very good and seemed to eliminate the necessity of flashing to prevent moisture intrusion.

7. Traditional training of skilled workers shifted to on the job training.

8. Traditional contractors shifted to workers being paid "by the piece".

9. Supervision by the General Contractor gave way to the subcontractors providing their own supervision and coordination.

10. Detailed plans and specifications were often replaced with minimal plans, "for permit".

11. Building inspectors were required to perform more and more inspections each day.

12. The building materials and techniques became more diverse and complicated.

13. New untested techniques and materials.

14. New materials not anticipated by the code required special "product approval".

15. Material and system "product approval" were dependent on the manufacturer for testing and certifications.

These changes were driven by the economy and demand for development. The powerful lobbies of different groups dictated many unwise changes in the building and construction industry. Each entity in the process of building a structure or facility was under pressure for more, faster and cheaper construction.

Building damage during the Hurricane Andrew, varied widely depending on the "type" of construction. The worst damage was suffered by Mobile Homes, now commonly called "manufactured homes". Mobile homes are the least structurally competent homes built. Manufactured homes have their own set of construction standards and are not required to meet normal building standards. The next most highly damaged category was multifamily homes. This category applies to both apartment and condominium buildings. Many of these buildings are multistory and/or multibuilding and contain hundreds of units in each complex. Single family homes, usually built in communities and often by several builders, showed the best comparison in different building techniques. The Miami Herald story clearly illustrated the different damage, depending on the type of home and the builder even in adjacent neighborhoods. The least 
damaged buildings were the higher end commercial buildings. These buildings generally had better plans, specifications, contractors and workers.

The public has been lured into a false sense of security by a variety of different factors. During news coverage of a hurricane, news organizations usually have several crews on the scene to document the worst damaged areas as the storm makes landfall. The public becomes complacent if the storm damage was minimal and news stories are limited to a few aluminum carports being blown away or the inevitable splash of waves against the seawall. "We have been through a hurricane" or "it won't happen here" syndrome is alive and well. When the public sees many storms come and go during a season with only a small area of severe damage, they realize that if the storm makes landfall 50 miles to either side of their.position, the damage, including flooding can vary widely. This makes them feel it is unnecessary to board up their windows and move to a safer location a day or two before the storm hits. St. Petersburg, Florida, a peninsula on the west side of Florida has recently determined that if a complete evacuation were to be required, people must be moving out at least 4 days prior to the storm arrival. Any experienced person knows the weather department cannot predict where the storm will hit 4 days prior to making landfall. Even if people want to evacuate the area, the roads are often filled with others hurrying to avoid the storm. An example of this occurred during the 1999 hurricane season. During hurricane "Floyd" many people on the southern end of the state evacuated North to avoid the storm. As the storm moved North the people trying to evacuate the areas to the North of that evacuation had no place to go, either in accommodations or roadways. Evacuation has became a practical impossibility in Florida. This leads the "experienced" to simply stock supplies, tape the windows, and ride out the storms. A new breed of storm experienced occupants feel they will simply have a "hurricane party" until the danger has passed. If you are in a building that has substandard construction you may be in danger of losing the building when the wind reaches a moderate 80 to $90 \mathrm{MPH}$. If you are in the tidal surge area you may be in danger from drowning by the tidal surge, even if the building survives. You cannot survive in the bathtub or closet if the high water drowns you.

The emergency agencies have finally agreed that beach communities cannot be effectively evacuated. The storm shelters in Florida areas generally can only accommodate 15 to 20 percent of the population. Now they are getting excited about increasing the building code requirements to make sure the damage to dwellings and shelters will be minimal. But as the experience with Andrew in Miami clearly showed, it was the failure to build to the current codes that caused the vast majority of the damage. Miami has increased the requirements to the point that many building materials and techniques are no longer viable. For instance, concrete tile roofs have long been a staple in the Florida housing 
market. The new Dade County regulations have made the fastening and testing requirements so stringent that the cost of a concrete tile roof has tripled. Major damage was caused by concrete roof tiles blowing off and hitting the adjoining houses or buildings. This should have been solved by making sure the tiles were fastened in accordance with the existing code requirements. The obvious solution for the builders has been to pick a new product that did not have these severe requirements. If the buildings are not built to the code, plans, and specifications it does not matter if the code requirements are made more stringent. The realistic solution would have been to assure the permit plans are designed to meet the code and the buildings have been constructed in accordance with the permit plans, specifications, and applicable codes.

To understand the complexities of the speculative construction market, especially as it pertains to the speculative housing market, we must study the different players in this very serious situation. Let's look at the participants in the speculative building process as it applies to multifamily and single family projects. The following is a discussion of each of the major participants in this process. Not all participants are present in each project, but several entities are always present:

\section{Developers' And Land Owners' Role}

DEVELOPER: The developer is the initial and driving force for most speculative projects. The developer must envision a project and decide if he can obtain control of the land, secure the plans and permits, arrange financing, build the buildings, sell the units and make a profit on the whole transaction.

$\mathrm{He}$ is in a very speculative position and typically looks for all possible ways to limit his risk and out of pocket money. Limiting the outlay of up-front cash is a prime motivation. Often if the land can be pledged as subrogation without an initial outlay of cash, the terms of the construction loan will be more favorable. The land owner would be offered an enticement of more profit if he waits to be paid until the project has been sold and proven successful.

The permit plans must be produced to obtain a building permit. The best way to have maximum flexibility during construction would be to have a minimal set of plans, just barely enough to qualify for a building permit. If the developer can act as the contractor, he will eliminate another potential conflict and increase his profits. However, acting as the contractor brings its own risk. so the legal entity must be carefully structured so that if the project fails, the developer can walk away without suffering devastating losses. These risks can often be packaged into a limited partnership or other legal corporations as a hedge against a project failure. 
LAND OWNER: Land is often the most expensive initial cost for the project. If the developer can entice the land owner to subrogate the land to secure the construction loan he is in a strong position to negotiate a lower point spread and interest rate. The financier will be secure with the pledge of the land to the project. Usually the land owner understands this relationship and will negotiate a very enticing part of the profits from the successful project.

\section{Architects' and Engineers' Roles}

ARCHITECT: Large condominium and multifamily projects require an Architect or Engineer to produce and "seal" the project plans. If the Architect produces a minimal set of plans, just barely sufficient to obtain a building permit, he can charge less money than producing a full set of properly detailed working drawings and specifications. His liability is usually less since the plans do not show most of the pertinent details required for construction. It is difficult to prevail in a legal suit for items not clearly defined in the plans, unless these missing items constitute negligence or a code violation.

ENGINEER: The engineers are in the same position as the architect. The developer will pay a minimal fee for a minimal set of plans. The requirement is to have barely enough plans to obtain a building permit. If the engineer produces a minimal set of plans, the engineer can charge less money and get more work. Many suppliers and manufacturers will "design" the system and specify the details for the engineer to use on the "permit plans". The manufacturer will furnish "boilerplate" specifications that sound good, but are designed to assure two things. First, to limit the product to the manufacturer producing the specifications, and second, to fool the permitting agencies into thinking the specifications are complete and meet the code.

The manufacturers will be careful to write the specifications to make it difficult for the forensic investigator to determine if the product was constructed correctly. The manufacturer will be very hesitant to help the investigator establish the product was applied improperly to help the unit owner prove why the system failed. To help the unit owner or forensic investigator prove the system was installed improperly would be alienate the developer, contractor and subcontractor. This is especially true in the speculative condominium market, where the manufacturer often must "help" the professional design the proper use of their material. If they help the unit owner prove the developer failed in their duty to construct the project properly, the word will spread quickly and that manufacturer will soon be out of business. After all, the developer buys the product not the unit owners.

\section{Public Attitudes and Understanding}

SALES: The condominium project may never get off the ground without a 
skillful sales team to sell the units. The best deals will be offered to the first buyers, usually before the building construction starts. "Pre-construction" reduction in prices are very enticing to the early unit buyer. The sales staff must be very adept at verbally assuring the potential buyer of the great reputation and "guaranteed" response of the developer to each complaint. The sales pitch usually includes many vague assurances of the building's quality for the buyer. However, the written contract for the sale carefully negates most of the assurances the customer felt during the pre-sale conversations. Trying to force a written contract to include the promises of the sales staff is usually futile. The seller will produce the written contract for the sale of the unit. If you insist on taking the contract to your attorney, they will use all the smooth tactics they can muster to avoid that review by your attorney. They know that if the attorney looks at their contract he will advise against signing it. Generally the contract clearly states that all verbal promises are not valid, and the written contract prevails. Many loopholes are in this contract to avoid letting the owner mount a successful challenge to the developer. Legal challenges are usually expensive, difficult and often futile for the unit owner. The well established developer will have experience in dealing with this contract and will usually prevail.

CONDOMINIUM ASSOCIATION: This association is a legal group of unit owners created to protect the entire building complex and not favor one owner over another owner's interests. The condominium association must balance the needs of all the owners and decide by majority vote, what and how to repair their building.

UNIT OWNERS: The individual unit owners are the buyers and ultimately responsible to protect their investment interests in the project. Without the individual unit purchase the project would not get to the completed stage. The unit cannot be re-sold for a realistic price if the second buyer knew of the problems encountered during construction. If the owner's unit is in the middle of the building, its problems may be far less than the more prized end or penthouse locations; and therefore their choice of building repairs may differ significantly with the other unit owners.

\section{Building Officials' Role}

BUILDING OFFICIAL: The building official is usually responsible, by state statute, to verify that the plans, specifications and construction meet the minimum requirements of the local building code. In Florida, it is required that each project meet the minimum requirements of a major building code. With the building boom of the past few years the building departments are having difficulty keeping pace with the plan verification and inspections required. Most of the building departments were developed to oversee small, repetitive homes and buildings. These departments are now helplessly understaffed and underfunded. 
Today many homes contain several thousand square feet of space and are complicated and difficult to inspect. Most of the single and multifamily homes have a minimal set of plans with poorly defined details and connections. It is not uncommon for local building departments to require 20 to 30 inspections per day by each inspector. These inspectors cannot adequately inspect 20 to 30 projects with the complex construction and minimal plans that are prevalent in today's market. The Pasco County Building Department recently made a suggestion to the county commissioners to have the contractor or developer furnish their own engineers to inspect and certify that the construction meets the plans and minimum code requirements. This is not a conducive environment for detailed and demanding inspections; it may also be an ethical conflict for the engineer to inspect and certify his own work.

The wood truss industry is one example of construction change. Twentyfive years ago the factory manufactured trusses were not feasible without repetitive simple layouts. In today's market with more complex buildings, computer generated truss designs, layouts, and fabrication, it is rare to have more than a few trusses of the same size. Coupled with the more stringent requirements for hurricane connections, the inspector's job is very complex and time consuming.

The burden of quality control has been shifted to the building department. When a problem surfaces, the first defense by the contractor will be "the building met and passed all the building department inspections." This is a convincing argument to a jury, trying to be fair, in adjudicating the case. However, the contractor still "legally" must control the quality of the construction. The jury rarely understands that distinction. Today's housing market rarely has a general superintendent on the job site. The subcontractors are left to control and coordinate their part with other trades, and pass the required inspections. Their payment is based on passing the required inspections. Rarely are the various trades sufficiently supervised to assure their work has been performed correctly and timely.

\section{Contractors', Subcontractors' and Workers' Roles}

CONTRACTORS: Assuming the developer does not act as the contractor, the contractor will need to build the project with the least amount of time and labor. In many instances the contractor provides only minimal coordination and quality control. When the contractor has been furnished with a minimal set of plans that contain few specific details and no professional observation he is free to select the most efficient method of building the project. Many items, such as drainage, site work, electrical and plumbing, are fairly well defined and understood by the inspectors and subcontractors, but the remaining construction is often left poorly defined and controlled. The building trades, using new and less familiar procedures, suffer under these conditions. The coordination of the trades involved in the building construction is often lacking. As an example; the 
waterproofing of the outside building envelope often involves several trades such as: metal studs, interior drywall, exterior drywall, window's, doors, flashing, EIFS, painting, and sealant. If these trades are not coordinated and controlled properly the building will suffer serious water intrusion consequences.

SUBCONTRACTORS: The subcontractor must "bid" the work involved and usually has to be the least expensive to gain the contract from the contractor or developer. With a minimal set of plans the subcontractor is allowed a wide latitude to define his own "standard of the industry". This is not a good atmosphere to obtain high quality work. The coordination of different trades can be expensive and time consuming for the subcontractor. The general contractor was the schedule controlling entity in years past; but in today's market rarely are the subcontractors tightly scheduled. On current job sites the developer or contractor will call the next sub when the previous sub has completed his work. This causes down time if the next sub cannot man the job for a week or more. When subcontractors must coordinate with each other the coordination becomes even more difficult.

WORKERS: Twenty five years ago the individual workers put the pieces together and worked for the contractor or subcontractor as an hourly employee. That is rare in today's fast paced construction market. Commonly, the worker will work "by the piece", i. e. a flat rate for each window or piece of material actually incorporated into the building. These workers often work in small groups and the leader of the group must pay the workers quickly, and many times in cash to get the work completed. His goal is to place as many "pieces" as possible in each pay period to pay his help and make a profit. This easily leads to not installing all the nails, screws, straps, anchors or fasteners that may be required by the engineer or manufacturer's literature to assure compliance with the load transfer required. If it is caught by the building inspector, the subcontractor simply installs the items the inspector found missing, not necessarily all the items required to meet the plans and code.

\section{Manufacturers' Roles}

MANUFACTURERS: Anchorage of wood and other material to the building requires a dependable load path to transfer the loads to the ground. The manufacturer must test and certify that a specified anchor will transfer the load listed in the catalog. These requirements are tested with proper ASTM tests and protocol and must meet rigid specified conditions. When the engineer looks at the catalog and selects an anchor to transfer the load, he must be aware of the conditions placed on that listed allowable load. Look at a typical example from a well known supplier of metal connectors. Somewhere in the table of loads it will refer to the test conditions that determined the load for that connector. Look at the note ' $\mathrm{e}$ ' in this example. "Unless othenvise noted, allowable loads are for 
use with No. 1 Doug' Fir-Larch under continuously dry conditions. Allowable loads for other species or conditions must be adjusted according to the code." No. 1 Doug' Fir-Larch is a good structural wood from Group II. However, most of the single family homes and multifamily units are constructed with SprucePine-Fir, Group III lumber, and sometimes even with Group IV wood. The following adjustments must be made to comply with the appropriate code. A reduction to $81 \%$ for material from Group III; and to $65 \%$ of load shown if using Group IV material. This allowable load is rarely reduced on minimum plans. They will state the manufacturer and the load certified by that manufacturer and specify "or equal". This becomes even more complicated when the worker decides to use a connector from the local building supply store that may be a different gage and even require less fasteners. The inspector would need to have all the relevant catalogs to properly cross reference each connector. Usually the inspector assumes if it has a connector it must be right because it is the workers responsibility to use an appropriate connector.

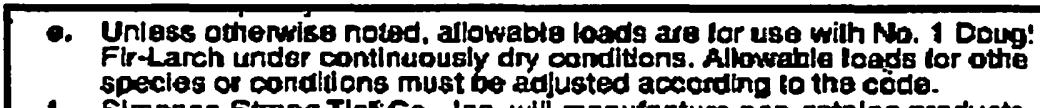

Catalog loads are tested and calculated for Group II wood, \#1.

Another example of misleading information was found at the local building supply store. A popular thin cardboard type structural thermal exterior board, that is very popular with the building industry in Florida, can be found in most building supply stores. Each 4' x 8' sheet is clearly stamped with marks for each nail, the nail size, test certification, and approval number. Also listed is a caution that if the sheet is not installed as specified, the material will not meet the code "product approval" for this product. The test number was clearly listed and stated it met the Standard Building Code requirements as shown in that product approval. A call to the Birmingham office of the Southern Standard

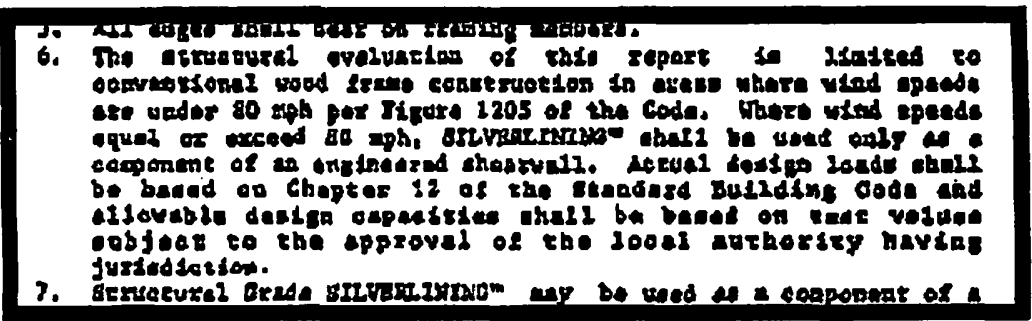

Example of Southern Standard Building Code Approval of a specific material with limitations. However this material is sold extensively in Forida, but nothing on the material indicates this limitation. It simply states it has "SBC approval $\$ 8587^{n}$ and gives very detailed nailing instructions. 
Building Code Congress failed to locate a copy of the test. Their reason was the manufacturer must maintain that test information. I called the manufacturer and with persistence obtained a copy of the test procedure and approval protocol for that particular material. On page 7 of 8 in the list of qualifications, Please note item 6. The $80 \mathrm{MPH}$ wind load limitation disqualifies this material from any project in the State of Florida. However, it is still widely used in projects all over Florida and the Southeastern United States where the wind load must meet $90 \mathrm{MPH}$ to $120 \mathrm{MPH}$. No areas in Florida or in the coastal areas of the Gulf or Atlantic have a wind speed requirement as low as $80 \mathrm{MPH}$. However, the material is still sold extensively in most of the building supply stores in those areas. When the inspector encounters this material on a building, and it clearly states it meets the Standard Building Code requirements per approval \#8587, he is in a difficult situation. Without a diligent search effort the real limitations are not known to the engineer, building department, workers, or the unit owner. But the contractor will be quick to point out that this material was approved for use by Standard Building Code and it was passed by the building department. That is true, but the limitations are rarely known or mentioned to the inspector. The building inspector is in a difficult position if he rejects the material that has been specified by the building designer and has been approved by the Standard Building Code or the Uniform Building Code. These actual test reports are sometimes available, but usually only by persistent calls to the manufacturer.

\section{Investigations}

FORENSIC INVESTIGATOR: The forensic investigator must establish the scope of the problem and identify the possible solutions. Often the problem is not known to the unit owner or condominium association. The initial request is often general in nature like, "we noted some water damage." The first step will be to identify why the water intrusion is present and what steps are required to repair the intrusion path. An inspection should be conducted to determine if the water intrusion was an individual occurrence or was representative of a common problem in the building. Next the collateral damage must be identified. If the water intrusion has been present for an extended time, from months to years, it is likely that structural damage has occurred that was not visible. This damage may be in the form of rot or termites in wood structures, reinforcing deterioration in concrete, or rust in metal structures. Small bore video cameras can be used to inspect the inside of walls without a major disruption of the interior finishes. However, if major deterioration was noted by the video inspection the wall finish must be removed to fully expose the extent of damage. Mold, rot, termite, rust or other deterioration may then be noted on the inside of the exterior wall surface. Often this damage will not be evident on the interior of the unit until the damage has progress to a critical stage. Replacement of the structural system may be required if the damage was extensive. It is not good to cosmetically repair the interior finish without investigating the reason for the deterioration. 
Knowing the problem and solution is not enough to have the developer or contractor properly fix the building. You must investigate and establish the legal proof and evidence required to prevail in the legal system. The investigator must be able to define the amount of damage, the cost to repair that damage, and the parties responsible for damage. This legal burden can be time consuming and costly. Without the detailed evidence to prove your case, your client will not succeed with a legal remedy. Sometimes the condominium association will opt to "fix" the building with paint and sealant. Be careful that such a solution will solve the problem. Do not let your position be compromised to make your client agreeable. It is. your responsibility to convey the full nature of the problem. Rarely will one party be responsible for the entire problem. Regardless which party has retained your services, your client attorney will need to know the extent of damage, the reason for the failure, and the parties responsible.

\section{Case Histories And Common Problems}

Let's look at some common problems that adversely affect the ability of the building to resist hurricane force winds and water intrusion.

METAL ANCHORS: Common metal anchors used between the wood and other materials are often used improperly, both by the designers and construction crews. It is common to find anchors that were not installed properly because the worker lacks the basic knowledge of which anchors are interchangeable or and how the anchors should be applied.

A typical example of poorly installed anchors was found in a completed house built by a large multi-state developer. The drywall was removed to inspect the installation and condition of the main anchors. The anchorage of the upper story frame construction to the masonry construction below required several anchors with 5000 pound capacity. The top of each anchor required bolting to the multiple studs in the framing above, and the anchor needed to be tightly connected by a large bolt to the concrete tie beam below. The top was bolted to multiple studs with two large horizontal bolts. Neither bolt was tight and the hole was oversized to allow easy bolt installation. The multiple studs also required fastening together to transfer the load from all the studs into the anchor. Each stud only had 4 or 5 nails to transfer the shear load to adjacent studs. The vertical anchor bolt nut was loose by 3-1/2". This would allow the top firaming to raise 3-1/2" before any load could be transferred to the vertical anchor bolt into tie beam below. While each anchor was theoretically capable of transferring 5000 pounds if installed properly, it was virtually useless as installed. In the manufacturers ASTM test protocol, a failure was defined as a differential movement of $1 / 8$ " between the upper structure and the lower structure. The presence of the loose nut to the anchor should have been immediately obvious to any competent framing inspector. Even with over 3-1/2 inches of 
movement evident, this installation passed the required framing inspection by a rather large municipal building department in Florida.

Other anchors in this same house required heavy metal strap anchors. embedded into the concrete tie beam, to be attached to the upper frame construction. These anchors required fifteen $16 \mathrm{~d}$ nails into the upper portion of each strap. When viewed from the inside, the nails were driven into the $3 / 8^{\circ "}$ plywood sheathing and did not engage the framing at all. The presence a cluster of 15 large nails that did not engage the upper framing should have been a red flag to any competent inspector. Again this passed the framing inspection. Workers seem to feel that if it is passed by the building department inspection, it doesn't matter how it was attached.

ROOF FLASHING: Another example of simplified construction can be found in most 3 in 1 shingle roofs at the wall intersection. In years past this would call for short step flashing at each shingle row. However with the sealants of today the roofers will install a continuous " $L$ " flashing and depend totally on a bead of sealant to prevent water intrusion. If the sealant were installed properly and fully, it would work for several years. The installer does not want to stop at each row and apply the sealant, so it has became customary to seal the entire length of " $L$ " flashing at one time and then apply the shingles. The sealant may be too thin or may flash dry before installation of the shingles. This would then become a path for water intrusion, especially during a hurricane. This water intrusion often results in loss of the drywall ceiling, a key component to prevent uplift failure of the truss system during a hurricane.

EXTERNAL INSULATION AND FINISH SYSTEM (EIFS): This new system includes attachment of the insulation and a thin exterior finish coat to the exterior of a building or structure. The finish is often referred to as 'fake stucco' and is prevalent on many buildings constructed in the past couple of decades.

EIFS typically is attached to a structural surface that has been specified and installed by other trades. The building designers, engineers, contractors, building departments, and workers rarely understand the limitations involved by using the EIFS system. Specifications frequently refer questions about the attachment of the substrate to the metal studs, for instance, to the EIFS manufacturer. The EIFS manufacturer will simply refer them to the engineer or architect for attachment specifications.

Most of the collateral trades assume the EIFS contractor knows and controls all the other trade interaction and will guarantee their part of the system has been installed correctly. However, the EIFS contractor will only assume responsibility for attachment of the insulation and the exterior finish. They will 
attach their insulation o the available exterior wall finish. The attachment of the exterior subsurface wall material to the framing is not the responsibility of the EIFS manufacturer or contractor.

EIFS requires a 'product approval' for use in areas where the Standard Building Code applies. The EIFS approval test uses a panel set up consisting of metal studs, with moisture resistant drywall attached with screws. However, the tests are conducted to assure the method of attachment of the insulation to the drywall does not fail. For this reason the drywall and studs have been purposely oversized to assure failure will not occur in the drywall or stud material. This system provides a good example of why the coordination between the different trades and sub contractors on the job is critical.

For instance, when the building designer specifies an EIFS system for the exterior finish, the window subcontractor must install the windows and flashing. A typical fixed window often consists of a commercial window frame that is known as a "wet system". This window system will shed most of the water, but it is known and expected to have some water intrusion at the frame joints and the window gaskets, especially

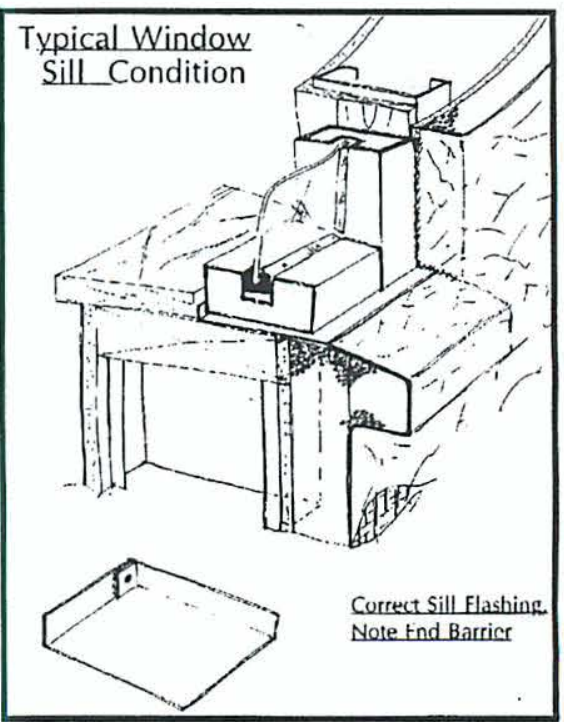

The flashing below the window must be turned up at the ends. at the corners. The window requires a sill flashing to shed that small amount of water to the outside and over the exterior finish. The flashing must be turned up on the ends as shown in the example at the right to prevent the water from flowing over the end of the flashing into the wall system. But the flashing can be installed faster and easier if it is a simple " $L$ " flashing. This water path must not be sealed from the outside with sealant or exterior finish material, because it will leak regardless of the amount of paint and sealant applied later.

When the building leaks after construction, the condominium association often will hire a waterproofing contractor to paint and caulk the building to prevent the water intrusion. Unless the painter caulks each material intersection completely, the water intrusion will persist. If they caulk each intersection between the glass and gaskets, gaskets and aluminum, aluminum to aluminum, and aluminum to finish material, they may be successful in stopping the water 
intrusion for a time. But, even if they successfully seal all the paths of water intrusion, the building will look dreadful because of the caulking material, and will require frequent repair. Caulking the window glass to the gaskets for instance, cannot be sealed with a neat appearance. This is a terrible price for the unit owner to pay for the simple failure, by the window installer, to turn up the flashing during the original construction as required. Often the painter does not understand the system and will caulk the intersection between the flashing and the aluminum window sill. This prevents the water from exiting below the window to the outside as designed, and forces the water into the wall system. This is an example of a critical detail that is not usually shown on the minimal "permit plans". If you have been retained to assure "quality construction" by the unit owner, you will have a difficult time getting the flashing bent up as needed without an extra cost to the unit owners contract. Even then it will be difficult to assure the correct flashing has been installed.

Another construction defect was found recently on an eight story condominium on the Florida East coast. The drywall was poorly attached to the metal studs on the exterior walls. During the investigation to determine the specified spacing of the drywall screws it was found that no specification existed for the spacing of the drywall screws that attached the drywall to the stud walls. The specifications referred from one section to another for the attachment of the moisture resistant drywall to the metal studs. The drywall specifications referred to the EIFS system specifications for attachment. The EIFS referred to the diywall section for the attachment. The "permit plans" were silent on the attachment of the drywall. The metal studs were defined on the structural plans, but the exterior finish was left to the minimal Architectural plans. The permit specifications simply referred to the manufacturers specifications. A search of the code failed to reveal a specific reference to EIFS, but the material had a "product approval" by the Standard Building Code. A study of the test report for the material "product approval" by Standard Building Code revealed the building contractor failed to attach the drywall as specified in the test for "product approval". This meant the drywall was not attached in accordance with the test protocol, therefore it was the drywall installer that failed to provide adequate screws to attach the drywall. Wrong! It was pointed out by the EIFS manufacturer that the test was for testing the adhesive, not the drywall to the building. The EIFS system would adhere to any suitable building wall material. The drywall material attachment was the responsibility of the wall subcontractor. No "product approval" or code reference existed for attachment of the drywall behind the EIFS system.

I contacted the drywall manufacturer to ascertain what the safe load carrying capacity of the drywall screws were for the moisture resistant drywall. They referred me to the engineer for design criteria. The engineer stated that he did 
not design the attachment of the drywall, that was an architectural decision. The Architect referred me to the EIFS manufacturer, who in turn referred me to the Architect, that referred me to the engineer. After a considerable amount of frustration, I discussed the situation with the technical personnel at the drywall manufacturers testing division. He told me to use 65\# per screw, but that is not official. When I calculated the amount of screws needed to attach the drywall, I found the drywall attachment capacity to the building metal studs to be approximately $10 \%$ to $40 \%$ of the load carrying capacity necessary.

The contractor assured me the screws were "all in the wall". He produced invoices showing the number of screws purchased. When we performed pull off tests to verify the load carrying capacity of the actual walls in place, we found handfuls of screws laying on the base channel, neatly "in the wall" as stated by the contractor. The pull off tests on 2' x 2' sections of wall panels, using standard ASTM test protocol confirmed the test panels were seriously under capacity for the code mandated wind loads. Each panel should have required approximately $250 \#$ per panel to pull it from the wall. The tests ranged from $0 \#$ (it fell off before we could hook up the test mechanism) to about 75\#. These tests were challenged by the developer as being not representative of the entire wall as a unit. After a long and protracted pre-trial negotiations the Condominium Association settled for about one fifth of the cost to replace or revise the walls. This did not address the missing $38 \%$ of the post tension strands in the floor slab.

POST TENSIONED FLOORS: The building was constructed with concrete columns, and post tensioned concrete tloors. The post tension cables had been observed and certified as being placed correctly by a large and well known testing laboratory. During the tensioning of the strands, the technician simply logged each strand tensioned in the tensioning log. No mention was made during the placement or the tensioning that up to $38 \%$ of the strands were missing and had never been installed. I simply counted the cables specified on the post tension plan and cross referenced to the tensioning report, and found $38 \%$ missing. Three floors did not have tensioning logs available, either at the building department or the contractor. To verify this situation existed in the construction, I rigged a swing stage and started to peel the stucco off the wall with a screw driver to verify the cables were missing. I immediately received a stop work order and very an emphatic denial and warning my work could jeopardize the safety of the workers and the residents, because I might damage a cable anchorage. The developer stated he, "would no longer be responsible for the structural integrity of the building because I looked at the ends of some of the post tensioned cables!" I received the warning and stop work order after I had verified two floors were missing $38 \%$ of the post tensioned strands required. 
The building department was not concerned with the defect because the developer assured them the building had stood for 4 years without a failure. The condominium association did not want to pursue the difficult and expensive procedure to prove the building may not be safe. My opinion was the building did not have the capacity they paid for nor the code mandated required live load capability. Without legal evidence of how much capacity was lost, the developer offered to settle for a monetary amount. The association was pleased because they could deposit the money in the bank to repair the building as necessary.

\section{Conclusion}

Buildings can be built to stand even winds in excess of $120 \mathrm{MPH}$, but the industry must enforce the codes and laws in place and not simply increase the code requirements after each disaster. Increasing the code requirements only impacts the honest builder and developer and costs their customers more for a home that must be overbuilt. If the contractor does not build to the existing codes, making the requirements more stringent will have no effect on their buildings. The fact remains that most buyers will not pay an extra amount for a building built to withstand the code mandated wind loads because all builders assure the customer their building has "passed the building department requirements." It is not uncommon to have the buyer place an undue emphasis on the price and much less emphasis on the overall quality of the project. Still, many contractors will build a good building that meets the applicable codes and will withstand hurricane force winds, simply by building to the existing code. This was evident in the damage comparison shown in the Miami Herald story, December 20, 1992. However the honest contractors are in competition with the unscrupulous developers or builders with greed for more and faster profits, regardless of the consequences to the public.

The above discussion represents barely the "tip of the iceberg" in the construction industry. What is the solution? How can we recover and have buildings built that will stand a reasonable code mandated wind loading? The first and primary effort must come from the public by demanding, and being willing to pay for buildings that are built in accordance with the existing laws and codes. Also insist immediately for enforcement of the existing laws concerning the design professional, building officials, contractors, and manufacturers. With the current building boom and economy it is doubtful this will happen, but we can all apply our influence to try to get the most egregious faults identified and solved.

\section{Reference}

1. Examples are from forensic investigations by this author, the identification of the specific projects have not been disclosed.

2. See the Miami Herald, December 20,1992, for complete coverage of their study. Excerpts will be quoted from that study throughout this article. 